\title{
AÇÕES DIGITAIS DO GRUPO PET ENFERMAGEM PARA A PREVENÇÃo DA COVID-19
}

SILVA, Maria Eduarda Pascoaloto ${ }^{1}$

BASTOS, Vitória Caroline Calister ${ }^{2}$

RIBEIRO, Saulo Guilherme Silva ${ }^{3}$

FURLAN, Mara Cristina Ribeiro ${ }^{4}$

RESUMO: Relatar a experiência do grupo PET Enfermagem da Universidade Federal de Mato Grosso do Sul, sobre a realização de ações digitais para a prevenção da COVID-19. A ação ocorreu por meio da gravação de seis vídeos que foram postados no perfil oficial do grupo pela plataforma Instagram, no modelo de IGTV. Os vídeos foram repostados pelos perfis individuais de cada membro do grupo para que ocorresse a maior propagação da informação para diferentes cidades e grupos de pessoas. Os temas dos vídeos foram: Higienização correta das mãos, uso da máscara cirúrgica, medidas a serem tomadas ao chegar em casa, limpeza de superfícies e objetos pessoais, isolamento domiciliar e higienização dos alimentos. Os vídeos obtiveram, ao todo, 1058 visualizações, 183 curtidas e 30 compartilhamentos na conta oficial do grupo na rede social denominada como Instagram. Os resultados desta ação foram positivos, tendo em vista a quantidade de público atingido, proporcionando a divulgação de informações acerca do vírus e forma de prevenção da doença.

PALAVRAS- CHAVE: Programa de Educação Tutorial; Divulgação Científica; Educação em Saúde; Ação de Extensão; Enfermagem.

\footnotetext{
${ }^{1}$ Graduanda em Enfermagem pela Universidade Federal de Mato Grosso do SulCampus de Três Lagoas. Bolsista PET-Enfermagem. E-mail: mepascoaloto@gmail.com

2 Graduanda em Enfermagem pela Universidade Federal de Mato Grosso do SulCampus de Três Lagoas. Bolsista PET- Enfermagem. E-mail: vitoria.calister@ufms.br

${ }^{3}$ Graduando em Enfermagem pela Universidade Federal de Mato Grosso do SulCampus de Três Lagoas. Bolsista PET-Enfermagem. E-mail: saulo_ribeiro@ufms.br ${ }^{4}$ Enfermeira. Doutora em Saúde e Desenvolvimento na Região Centro-Oeste. Docente do curso de graduação e pós graduação em Enfermagem da UFMS/CPTL. Tutora PET-Enfermagem. E-mail: maracristina.mga@gmail.com
} 


\title{
DIGITAL ACTIONS OF THE PET ENFERMAGEM GROUP FOR THE PREVENTION OF COVID-19
}

\begin{abstract}
To report the experience of the PET Nursing group at the Federal University of Mato Grosso do Sul, in the implementation of digital actions for the prevention of COVID-19. The action took place through the recording of six videos that were posted on the official profile of the group through the Instagram platform, using the IGTV model. The videos were republished by the individual profiles of each member of the group so that the greatest dissemination of information occurred in different cities and groups of people. The themes of the videos were: Correct hand hygiene, wearing a surgical mask, steps to be taken when arriving home, cleaning surfaces and personal objects, home isolation and food hygiene. The videos obtained a total of 1,058 views, 183 likes and 30 shares on the group's official account on the social network Instagram. The results of this action were positive, considering the amount of public reached, providing the dissemination of information about the virus and how to prevent the disease.
\end{abstract}

KEYWORDS: Tutorial Education Program; Scientific divulgation; Health education; Extension Action; Nursing.

\section{INTRODUÇÃO}

A crescente quantidade de casos de Síndrome Gripal na China em dezembro de 2019, despertou atenção das autoridades em saúde locais. A doença foi identificada como Covid-19, uma infecção causada por um novo Coronavírus, de alta taxa de propagação. Tão logo, no final de janeiro de 2020, a quantidade de casos espalhados pelo mundo tornou-se tão expressiva que a Organização Mundial de Saúde (OMS) declarou emergência internacional de Saúde Pública, e posteriormente, em março, pandemia (WHO, 2020).

Dias e Ribeiro (2020) ressaltam que a doença causada pelo novo Coronavírus pode causar comprometimento respiratório de gravidade variável, sendo pacientes acometidos desde assintomáticos, com resfriados 
comuns a pneumonias fatais. Em consonância com tal afirmativa, pôde-se perceber no mundo grande quantidade de indivíduos curados, como também milhares de mortos.

Segundo a Organização Pan-Americana da Saúde (OPAS, 2020a), a disseminação desse vírus ocorre de maneira acelerada por propagar-se por via aérea, através de gotículas suspensas no ar. Ainda de acordo com a mesma instituição, as medidas de proteção indicadas para frear as infecções são: o incentivo ao isolamento social, higienização correta das mãos e alimentos, uso de máscaras de proteção, evitar aglomerações e procurar as unidades de saúde apenas com sintomas graves.

O avanço repentino de uma doença até então desconhecida e de tão alta transmissibilidade gerou medo nas populações, uma vez que não existia preparo para seguirem as medidas de biossegurança. Frente a tantos desafios, o uso das tecnologias como instrumento de educação em saúde ganhou destaque mundial. Acredita-se que o avanço em tecnologias interativas em saúde pode ser uma opção efetiva e segura para facilitar a interação e a troca de informações entre profissionais da saúde e pacientes (CELUPPI et al, 2021).

Neste cenário, o Programa de Educação Tutorial surge no âmbito acadêmico, segundo a portaria MEC no 976 de 27 de julho de 2010, em seu artigo $2^{\circ}$, como um instrumento não só para "estimular a formação de profissionais e docentes de elevada qualificação técnica, científica, tecnológica e acadêmica", como também para "formular novas estratégias de desenvolvimento e modernização do ensino superior no país" (BRASIL, 2010).

A partir dos princípios de cooperação, diversidade, trabalho interdisciplinar e busca pela transformação social apontados por Feitosa e Dias (2019), os acadêmicos, em especial petianos, tornaram-se personagens cruciais para difundirem o conhecimento científico através das redes sociais de maneira simples, a fim de proporcionar o entendimento coletivo das técnicas corretas de prevenção do contágio. 
Diante do exposto, o grupo PET Enfermagem da Universidade Federal de Mato Grosso do Sul, campus de Três Lagoas (UFMS/CPTL), desenvolveu um projeto de ensino e extensão que criou vídeos informativos com conteúdo científicos transformados em dicas cotidianas de fácil acesso a toda população sobre COVID-19. O material foi divulgado nas redes sociais, local de maior circulação e alcance. Este artigo objetivou relatar a experiência deste projeto, que visou promover orientações sobre a prevenção da COVID19 por meio de ações digitais.

Neste trabalho, serão abordados os seguintes tópicos: Relato de experiência, que trata, de forma detalhada, dos passos executados para a organização e execução do projeto, bem como das vivências e aprendizados adquiridos, do ponto de vista dos petianos que dele participaram; Discussão, que permite um diálogo entre os achados na literatura e a experiência vivenciada pelos participantes do projeto; e Considerações Finais, que demostra uma síntese sobre todo o projeto e, para além disso, descreve as conclusões dos autores.

\section{RELATO DE EXPERIÊNCIA}

Trata-se de um relato de experiência acerca das vivências dos alunos do grupo PET Enfermagem ao planejarem e executarem a ação de ensino e extensão.

Participaram do projeto sete petianos, na faixa etária entre 20 e 23 anos, todos acadêmicos de enfermagem da Universidade Federal de Mato Grosso do Sul. Seis petianos gravaram os vídeos educativos, mostrando, na prática, ações preventivas no enfrentamento à COVID-19 e uma petiana realizou a edição e conversão dos vídeos para mídias sociais por meio do programa de produção visual Sony Vegas $P R O^{\circledR}$

A mídia do projeto foi convertida em um formato que procurava otimizar a visualização em modo mobile, ou seja, assistida por meio do celular. A postagem dos vídeos foi realizada no período de março a abril de 
2020, na plataforma Instagram no formato de "IGTV", no perfil oficial do grupo PET Enfermagem, da Universidade Federal de Mato Grosso do SulCampus de Três Lagoas, e republicado nos perfis individuais de cada membro do grupo.

Inicialmente, foi realizado um levantamento bibliográfico, sobre o vírus, sua propagação, formas de prevenção e de biossegurança, a fim de criar conteúdos digitais com embasamento científico quanto à prevenção contra o vírus. As pesquisas foram realizadas por meio das bases de dados Scielo e BVS, utilizando as palavras-chave COVID-19, Coronavírus e prevenção e leituras de publicações do Ministério da Saúde do Brasil e da Agência Nacional de Vigilância Sanitária do Brasil (ANVISA). Posteriormente, foram levantados e divididos os temas mais importantes e que suscitavam mais dúvidas à população frente ao coronavírus. A linguagem utilizada nos vídeos foi informal, já que o público-alvo se tratava da população em geral. Seguem as temáticas dos vídeos:

Vídeo 1 - Higienização correta das mãos (Link https://www.instagram.com/tv/B-pMrwn oQ/?utm source=ig web copy link): demostrou a forma correta de higienização simples das mãos, utilizando tinta guache vermelha, o sabão líquido, água, papel higiênico e toalha de pano (ANVISA, 2009). A técnica foi orientada e apresentada no vídeo como descrito abaixo:

1. Distribui-se por todas as mãos uma tinta do tipo guache na cor vermelha simulando a sujidade e os vírus presentes em nossas mãos no dia a dia;

2. Realizamos e orientamos a técnica, a partir do passo a passo para a lavagem simples das mãos, bem como os produtos que podemos utilizar e como realizar a secagem das mãos.

Vídeo 2 - Uso da máscara cirúrgica Link do vídeo (Link: https://www.instagram.com/tv/B-APcpJUOy/?utm source=ig web copy link): Utilizou-se máscaras cirúrgicas para demonstrar a utilização e manipulação das mesmas (COFEN, 2020; ANVISA, 2020). Seguem as orientações 
prestadas:

1. Partes que compõem a máscara cirúrgica descartável;

2. Passo a passo da colocação da máscara pelos elásticos e ajustes no clipe nasal;

3. Diferenças entre as máscaras de elástico e amarração;

4. Retirada da máscara cirúrgica;

5. Tempo de uso da máscara cirúrgica;

6. Adequações realizadas com a máscara de tecido frente as recomendações do Ministério da Saúde postadas em rede social oficial da entidade governamental.

Vídeo 3 - Medidas a serem tomadas ao chegar em casa (Link: https://www.instagram.com/tv/B--dtFSJzYt/?utm source=ig web copy link):

Orientou-se quanto às medidas a serem tomadas ao retornar para casa após a ida a supermercados, farmácias e entre outros (BRASIL, 2020a; MATO GROSSO DO SUL, 2020). Utilizou-se caixa de papelão, álcool em gel, sacola plástica, e álcool a 70\%. A gravação prestou orientações desde o momento de chegada do indivíduo na porta de sua casa e orientações sobre as formas de diminuir a contaminação do coronavírus.

Vídeo 4 - Limpeza de superfícies e objetos pessoais (Link: https://www.instagram.com/tv/B_BCevQpn2G/?utm_source=ig_web_copy_link ): Realizou-se passo a passo para que as técnicas fossem passadas aos telespectadores (DOREMALEN, et al, 2020; ANVISA, 2010). Foi utilizado para a gravação um telefone celular, flanela, borrifador, balcão, banco, notebook, chaves, capinha de celular e produto de limpeza. Os procedimentos realizados e orientados no vídeo estão descritos abaixo:

1. Primeiramente, foi discutido sobre os produtos de limpeza corretos para cada superfície e objeto, sendo o álcool a 70\% o mais indicado para a limpeza de superfícies no geral e objetos como chaves entre outros, e o álcool isopropílico para eletrônicos. 
2. Em seguida, foi explicitado sobre os panos de limpeza e a importância de borrifarmos o produto de limpeza sempre neste, e nunca na superfície que iremos limpar.

3. Ao final, orientamos sobre os movimentos corretos de realizarmos a limpeza manual e a quantidade de produto certa para diminuir a carga viral na área de limpeza.

Vídeo 5 - Isolamento domiciliar para casos confirmados de COVID-19 (Link: https://www.instagram.com/tv/B DiRrQpx e/?utm source=ig web copy link: Discorreu-se sobre como proceder os cuidados em casa frente aos casos confirmados para a COVID-19 (BRASIL, 2020b). As informações mencionadas e orientadas no vídeo foram: o isolamento do paciente, as precauções do cuidador e as precauções gerais frente ao isolamento domiciliar.

Vídeo 6 - Higienização dos alimentos (Link do vídeo: https://www.instagram.com/tv/B OUfZFpXk2/?utm source=ig web copy link) : Abordou-se como realizar a higienização dos alimentos e compras da forma correta (FINGER, LIMA, 2020; CASTRO, 2020; ANVISA, 2020). Para demonstração foram utilizados legumes e frutas, hipoclorito de sódio (água sanitária), uma bacia com água e saco plástico. O vídeo contou com o passo a passo da higienização de cada uma das compras, verduras e legumes mais utilizados pela população.

Os vídeos postados obtiveram, ao todo, 1058 visualizações, 183 curtidas e 30 compartilhamentos até o momento. Espera-se, com isso que as informações passadas tenham chegado em uma pequena parcela da sociedade, e que esta possa ser agente de multiplicação dos conhecimentos adquiridos com essa atividade de ensino e extensão universitária.

Dentre os benefícios do projeto, estão a aquisição de informações complementares sobre medidas de biossegurança para a prevenção à COVID19 por parte dos petianos, já que os mesmos se dispuseram a pesquisar em bases científicas confiáveis e oficiais acerca da temática abordada, uma vez que deveriam tomar domínio sobre as informações para disseminá-las de forma correta e responsável, e a chegada de informações técnicas e 
científicas, com uma linguagem informal, para a população como um todo, contribuindo para a consciência coletiva acerca da prevenção à COVID-19.

\section{DISCUSSÃO}

Tendo em vista o cenário caótico e de escassez de informações, a pandemia impôs a necessidade de novas estratégias e adequações para a atuação de profissionais e da própria sociedade frente à realidade de distanciamento social (CELLUPI, et al. 2021).

Tendo essa perspectiva em vista, enfatiza-se a importância da consolidação do setor de eHealth (uso da tecnologia para a prática de cuidados e educação em saúde) no cenário atual brasileiro e mundial como uma estratégia eficaz para melhorar a qualidade do cuidado e expansão do acesso aos serviços de saúde e informações verídicas acerca das formas de enfrentamento da pandemia (CELLUPI, et al. 2021).

Para Souza et al. (2020), a demanda mais recente da sociedade refere-se ao conhecimento correto sobre os assuntos que circundam a COVID-19, dada a preocupação dos profissionais de saúde e estudiosos para com a circulação de fake news, cada vez mais evidente. O projeto trouxe contribuição para o suprimento dessa demanda, uma vez que levou, de maneira didática e informal, informações importantes e pertinentes às maneiras corretas de se prevenir contra a COVID-19.

Para promover a saúde é necessário promover mutuamente um cuidado empoderado e o bem-estar. A ideia de poder trazer uma forma eficaz de deixar pessoas longe da contaminação pela forma mais recente de variação do coronavírus, por meio de ações simples, como a gravação de um vídeo educativo, fornece empoderamento a futuros profissionais e educadores em saúde, bem como, a ação de assistir a esses vídeos, traz, reciprocamente, um autocuidado empoderado ao receptor do conhecimento (SOUZA, et al. 2020).

Transformação digital em saúde significa pôr a saúde pública em primeiro plano na era da interdependência digital, não apenas com o atendimento digital ou o uso maior do computador e aplicativos ao prestar 
atenção à saúde, mas também na aquisição de conhecimentos científicos, seja de forma técnica (por parte dos profissionais e estudiosos), seja de forma informal (por parte da sociedade como um todo). $E$ isso requer o firme compromisso de aprimorar as soluções a partir de dados com foco na atenção centrada na pessoa (OPAS, 2020b).

Diante da então imposição de novas estratégias para a chegada da educação em saúde ao público em meio ao distanciamento social, unida à eficácia do eHealth na levada de informações de forma eficaz e segura, o grupo PET Enfermagem, a fim de cumprir "sérios compromissos epistemológicos, pedagógicos, éticos e sociais", seguidos pelo Manual de Orientações Básicas do PET (BRASIL, 2006) acreditou que o projeto supracitado seria uma forma eficaz não somente de levar educação em saúde aos usuários do Instagram, mas, principalmente, de tornar possível a "melhor qualificação dos alunos como pessoa humana e como membro da sociedade".

\section{CONSIDERAÇÕES FINAIS}

A realização dos vídeos possibilitou aos integrantes do grupo PET adquirir informações acerca do tema e do uso das plataformas digitais, além de promover a educação em saúde e o maior contato do grupo com a população.

Os petianos, além de se capacitarem na utilização das plataformas digitais, também aprimoraram os conhecimentos sobre o coronavírus e criaram meios de orientar a população, respeitando o distanciamento social, sobre o novo vírus que cada dia mais se aproximava dos cidadãos brasileiros, o que trouxe uma experiência nova e exitosa para o grupo.

Ademais, notou-se a relevância das mídias digitais como estratégia para o enfrentamento da pandemia de COVID-19, e o combate às notícias fraudulentas, as chamadas "fake news", principalmente devido às diversas pesquisas ainda em desenvolvimento. Os vídeos passaram informações precisas e coesas, de acordo com cada portaria e nota de esclarecimento que era lançado pelos órgãos de saúde do Brasil, levando para o público a abordagem da doença e melhores tomadas de decisões. 


\section{REFERÊNCIAS}

ANVISA. Agência Nacional de Vigilância Sanitária. Segurança do Paciente em Serviços de Saúde: Higienização das Mãos. Agência Nacional de Vigilância Sanitária. Brasília: Anvisa, 2009. Disponível em: < https://bvsms.saude.gov.br/bvs/publicacoes/seguranca_paciente_servicos_ saude_higienizacao_maos.pdf > Acesso em: 27 abril 2021.

Agência Nacional de Vigilância Sanitária. Segurança do paciente em serviços de saúde: limpeza e desinfecção de superfícies. Brasília: Anvisa, 2010. Disponível em: < https://www.gov.br/anvisa/ptbr/centraisdeconteudo/publicacoes/servicosdesaude/publicacoes/manualde-limpeza-e-desinfeccao-de-superficies.pdf/view> Acesso em: 27 abril 2021.

Nota técnica GVIMS/GGTES/ANVISA n 04/2020 - Orientações para serviços de saúde: medidas de prevenção e controle que devem ser adotadas durante a assistência aos casos suspeitos ou confirmados de infecção pelo novo coronavírus (SARS-COV-2). Brasília: Anvisa, 2020. Disponível em: <https://www.gov.br/anvisa/ptbr/centraisdeconteudo/publicacoes/servicosdesaude/notas-tecnicas/notatecnica-gvims ggtes anvisa-04 2020-25-02-para-o-site.pdf> Acesso em: 27 abril 2021.

BRASIL. Ministério da Educação. Portaria MEC no 976, de 27 de julho de 2010, publicada no D.O.U em 28/07/2010. Portaria MEC no 591, de 18 de junho de 2009, com as alterações da Portaria MEC no 975, de 27 de julho de 2010. Brasília: Diário Oficial da União, 28 de jul 2010. p. 103-104.

Disponível em: <http://portal.mec.gov.br/index.php?option=com docman\&view=downl oad\&alias $=6647$-portaria-mec-976-27-07-2010\&category slug=setembro2010-pdf\&Itemid=30192> Acesso em 30 março 2021.

. Ministério da Saúde. Orientações do Ministério da Saúde sobre Covid-19. 2020a. Disponível em: <https://coronavirus.saude.gov.br/sobrea-doenca\#se-eu-ficar-doente> Acesso em: 30 março 2021.

Secretaria de Atenção Primária à Saúde (SAPS). Protocolo de manejo clínico do coronavírus (COVID-19) na atenção primária à saúde. Brasília, 2020b. Disponível em: <https://portalarquivos2.saude.gov.br/images/pdf/2020/marco/24/202003 23-ProtocoloManejo-ver05.pdf> Acesso em: 27 abril 2021.

Ministério da Educação. Programa de Educação Tutorial. Programa de Educação Tutorial- PET. Manual de Orientações Básicas PET. Brasília, 2006. Disponível em:

<http://portal.mec.gov.br/sesu/arquivos/pdf/PETmanual.pdf> Acesso em: 26 abril 2020.

Revista Eletrônica do Programa de Educação Tutorial - Três Lagoas/MS - v. 3, n. 3, Outubro 2021, p. 70-76.

ISSN 2675 - 1003 
CASTRO, M. T. Comprando alimentos durante a pandemia de Covid-19. Food Safety $\quad$ Brazil, $2020 . \quad$ Disponível em: <https://foodsafetybrazil.org/comprando-alimentos-durante-pandemia-decovid-19/> Acesso em: 15 abril 2020.

CELUPPI, I. C.; LIMA, G. S; ROSSI, E.; WAZLAWICK, R. S.; DALMARCO, E. M. Uma análise sobre o desenvolvimento de tecnologias digitais em saúde para o enfrentamento da COVID-19 no Brasil e no mundo. Cadernos de Saúde Pública, Rio de Janeiro, v.37, n.3, 2021. Disponível em <http://www.scielo.br/scielo.php?script=sci_arttext\&pid=S0102311X20210 $00303001 \&$ Ing $=$ pt\&nrm=iso $>$ Acesso em: 30 mar. 2021.

COFEN. Conselho Federal de Enfermagem. Cartilha: orientações sobre a colocação e retirada dos equipamentos de proteção individuais EPIs. Brasília, 2020. Disponível em: < http://www.cofen.gov.br/wpcontent/uploads/2020/03/cartilha_epi.pdf> Acesso em: 27 abril 2021.

DIAS, E. G.; RIBEIRO, D. R. S. V. Manejo do cuidado e educação em saúde na atenção básica na pandemia do coronavírus/Care management and health education in the primary care in the coronavirus pandemic. Journal of Nursing and Health, v. 10, n. 4, 2020. Disponível em: < https://periodicos.ufpel.edu.br/ojs2/index.php/enfermagem/article/view/19 092> Acesso em: 30 março 2021.

DOREMALEN, N. V.; MORIS, M. G.; GAMBLE A.; WILLIAMSON, B. N.; TAMIN A.; HARCOURT, J. L.; et al. Aerosol and Surface Stability of SARS-CoV-2 as Compared with SARS-CoV-1. The New England Journal of Medicine. Massachusetts, v. 382, n. 16, 2020. Disponível em: <https://www.nejm.org/doi/pdf/10.1056/NEJMc2004973?articleTools=true >. Acesso em: 27 abril, 2021.

FEITOSA, R. A; DIAS, A. M. I. Articulação entre ensino, pesquisa e extensão: Contribuições do programa de educação tutorial (PET) para a formação de graduandos em Biologia. Educação \& Formação, v. 4, n. 3, p. 169-190, $2019 . \quad$ Disponível em: <https://revistas.uece.br/index.php/redufor/article/view/819/1315> Acesso em: 30 março 2021.

FINGER, J. A. F.; LIMA, E. M. F. Comunicação e prevenção da COVID-19: Papel dos alimentos e da proteção individual- Orientações gerais FCF/USP. São Paulo, 2020. Disponível em: < http://forc.webhostusp.sti.usp.br/forc/arquivos/paginas/Cartilha\%20\%20Co vid-19.pdf> Acesso em: 27 abril 2021.

MATO GROSSO DO SUL. Secretaria de Estado de Saúde. Manual de Condutas para enfrentamento do COVID-19. Campo Grande, MS. 2020.

OPAS. Organização Pan-Americana de Saúde. Folha informativa COVID- 
19 - Escritório da OPAS e da OMS no Brasil. 2020b. Disponível em: <https://www.paho.org/pt/covid19> Acesso em: 19 abril 2021.

. Organização Pan-Americana da Saúde. O potencial das tecnologias da informação de uso frequente durante a pandemia. Departamento de evidência e inteligência para ação em saúde. Washington, 2020a. Disponível em:

https://docs.bvsalud.org/biblioref/2020/07/1103374/factsheettics_por.pdf> Acesso em: 19 abril 2021.

SOUZA, C. T. V., et al. Cuidar em tempos da COVID-19: lições aprendidas entre a ciência e a sociedade. Cadernos de Saúde Pública. Rio de Janeiro, v. $36,2020 . \quad$ Disponível em: <https://www.scielo.br/scielo.php?script=sci_arttext\&nrm=iso\&lng=pt\&tlng =pt\&pid=S0102-311X2020000606002> Acesso em: 19 abril 2021.

WHO - World Health Organization. Comitê de Emergência sobre o Novo Coronavírus. 2020. Disponível em: <https://www.who.int/directorgeneral/speeches/detail/who-director-general-s-statement-on-ihremergency-committee-on-novel-coronavirus> Acesso em: 19 abril 2021.

Recebido em: 30 de Abril de 2021. Publicado em: 31 de Outubro de 2021. 